\title{
Construções concessivas e concessivo-condicionais com ainda
}

que

\author{
Michel Gustavo Fontes \\ Universidade Federal de Mato Grosso do Sul (UFMS) \\ Três Lagoas, Mato Grosso do Sul, Brasil \\ michelgfontes@gmail.com
}

DOI: http://dx.doi.org/10.21165/el.v45i1.751

\begin{abstract}
Resumo
Este artigo, tomando, como objeto de estudo, a forma ainda que, objetiva verificar a natureza das relações instauradas por ainda que na articulação de orações e lançar algumas ideias a respeito de seu estatuto gramatical. Como resultado, observa-se que a forma ainda que é polifuncional (KORTMANN, 1997), podendo instaurar relações concessivo-condicionais e concessivas (KÖNIG, 1985a; 1985b; 1986), o que evidencia seu alto grau de gramaticalidade.
\end{abstract}

Palavras-chave: ainda que; concessivas; concessivo-condicionais.

\section{Concessive and Concessive Conditional Constructions with ainda que}

\begin{abstract}
This paper, which has the form ainda que as its study object, aims to analyze the nature of the relations established by ainda que in the combination of adverbial clauses, and to discuss some ideas about its grammatical status. The results reveal that ainda que is polyfunctional (KORTMANN, 1997) and combines sentences both in a concessive and in a concessive conditional relation (KÖNIG, 1985a; 1985b; 1986), which evidences its high degree of grammaticality.
\end{abstract}

Keywords: ainda que; concessives; concessive conditionals.

\section{Considerações iniciais}

As conjunções concessivas, conforme Cunha e Cintra (2001, p. 586), “iniciam uma oração subordinada em que se admite um fato contrário à ação principal, mas incapaz de impedi-la." As gramáticas tradicionais costumam trazer uma lista de itens que podem cumprir o papel de conjunção concessiva. São exemplos mais frequentes as seguintes formas: embora, conquanto, ainda que, mesmo que, posto que, bem que, se bem que, por mais que, por menos que, apesar de que, nem que.

Os conectivos concessivos, segundo König (1985a; 1985b; 1986), apresentam algumas particularidades em comparação a outras classes de conectivos. A primeira diz respeito a sua etimologia e a sua composição, de natureza bastante transparente: os conectivos concessivos são geralmente complexos, isto é, são formados a partir da combinação de itens já disponíveis na língua, de forma que, além de serem facilmente relacionados a outro(s) significado(s), seus componentes podem ser identificados em sua forma e em seu significado. Por outro lado, os conectivos concessivos se desenvolvem tardiamente na história das línguas, e novos elementos são constantemente adicionados a sua classe. Um exemplo disso, no português, é a emergência da conjunção 
concessiva embora, que deriva do sintagma preposicionado em boa hora, usado para expressar bom augúrio (NEVES, 1998; FELÍCIO, 2008; CASTILHO, 2010). A partir da redução fonológica de tal sintagma, surge a forma embora, que passa a veicular valores espaciais, como em passou um caminhoneiro e levou ela embora... (cf. FELÍCIO, 2008, p. 127) e concessivos, como em enfim... foi uma::/ foi gratificante... embora eu tenha perdido a eleição (cf. FELÍCIO, 2008, p. 120).

Ao caracterizar as construções concessivas no português, Neves (1999) distingue dois tipos: as de caráter factual, chamadas de concessivas (cf. (1a)), e as de caráter eventual, chamadas de condicionais-concessivas (cf. (1b)). ${ }^{1}$ A diferença reside no fato de que, nas construções concessivas, os conteúdos proposicionais expressos tanto pela oração principal como pela oração subordinada são verdadeiros, e, nas construções condicionais-concessivas, somente o conteúdo da proposição principal é verdadeiro, enquanto o da subordinada é hipotético, podendo ser verdadeiro ou falso. Para a autora, no português, essa subcategorização das construções concessivas está relacionada ao tipo de conectivo. Enquanto os conectivos embora, se bem que e apesar (de) que instauram, exclusivamente, relações concessivas factuais, os conectivos mesmo que, ainda que e por mais que podem ocorrer tanto em concessivas factuais como em concessivas eventuais (ou condicionais-concessivas, nos termos de Neves (1999)).

(1) a contei também o número de estudantes ... quarenta e um ... e: eu tenho quase certeza, embora não tenhamos a lista (NEVES, 1999, p. 549, grifo do autor)

b nós temos as reuniões ... muito mais participação, porque, mesmo que alguns professores faltem porque tenham outros ... outros afazeres no ambulatório, mas sempre tem um bom número de reuniões (NEVES, 1999, p. 548, grifo do autor)

Frente a esse quadro de funcionamento discursivo dos conectores concessivos, o interesse deste trabalho recai sobre a forma ainda que, especificamente sobre orações articuladas por meio da perífrase conjuncional ainda que. Com base em dados extraídos do Córpus do Português (DAVIES; FERREIRA, 2006) $)^{2}$, a proposta central de investigação está em verificar a natureza da(s) relação(ões) instaurada(s) na articulação entre orações por meio de ainda que. Com base nos trabalhos de Neves (1999), König (1985a; 1985b; 1986) e Haspelmath e König (1998), descrevem-se as propriedades semânticas da construção "ainda que p, q", verificando como tal articulação se enquadra no esquema para a concessão: "embora p,q" $\rightarrow$ "se p, então normalmente não q". Especificamente, centra-se atenção no caráter factual ou hipotético da oração introduzida pela forma ainda que, notando o tipo de relação estabelecida na construção: se factual ou semifactual/eventiva (HASPELMATH; KÖNIG, 1998; NEVES, 1999).

Um segundo objetivo deste trabalho está em lançar algumas considerações iniciais a respeito do estatuto gramatical da forma ainda que. Segundo Galbiatti (2008), a investigação do grau de integração reflete o estágio de mudança de uma perífrase conjuncional à medida que quanto maior for a integração entre a oração subordinada e a principal, mais avançado o processo de gramaticalização. Dessa forma, ancorado em Traugott (1989), Sweetser (1990) e Lehmann (1988), levantam-se algumas propriedades que permitem atestar o elevado grau de gramaticalidade de ainda que.

\footnotetext{
1 Neves (1999) denomina as construções concessivas eventuais de condicionais-concessivas. Neste trabalho, opta-se por seguir com a denominação utilizada por Parra (2016): concessivo-condicionais.

2 Disponível online em <www.corpusdoportugues.org >.
} 
Este texto se organiza em duas partes. A primeira descreve a natureza das relações instauradas por ainda que. A segunda traz algumas considerações a respeito do grau de gramaticalidade de ainda que, evidenciando uma possível trajetória de mudança linguística. As considerações finais fecham o artigo, trazendo uma síntese dos dados alcançados.

\section{A natureza das relações instaurada por ainda que}

Em meio à difusa zona adverbial da articulação de orações (cf. NEVES, 2008), há uma série de relações adverbiais bastante aparentadas, que Kortmaan (1997) opta por agrupar sob o rótulo de CCC: Causa, Condição e Concessão. Segundo Neves (2012, p. 76), desde sua configuração cognitivo-perceptual, as construções causais, condicionais e concessivas são altamente relacionáveis, uma vez que as três manifestam, basicamente, relações de causalidade, compreendidas num sentido mais amplo.

As construções causais tipicamente envolvem junção (NEVES, 2012, p. 162), conectando uma causa a sua consequência, ou uma causa a seu efeito. As construções condicionais, por outro lado, ao condicionar a realização de um evento a outro, envolvem uma disjunção marcada pela eventualidade dos segmentos disjuntos, de forma que entre os dois segmentos conectados se estabelece um vínculo causal hipotético (cf. NEVES, 2012, p. 175). As construções concessivas, por fim, articulam dois fatos incompatíveis, isto é, destaca-se um fato apesar do qual a proposição principal se mantém (NEVES, 2011, p. 865). Dessa forma, conforme Neves (2012, p. 173), há, nas construções concessivas, uma relação causal não efetivada e uma relação condicional não preenchida.

As construções concessivas, segundo König (1985a; 1985b; 1986), distinguemse das condicionais pelo tipo de relação implicativa (entailment, no inglês) que se estabelece entre antecedente (p) e consequente (q). No esquema em (2), observa-se que, nas construções condicionais de forma se $p$, então $q$, tanto o antecedente como o consequente não são implicados pela enunciação da construção, e, assim, tanto antecedente como consequente são hipotéticos. Já em construções concessivas de forma embora p, q, conforme o esquema em (4), tanto o antecedente como o consequente são implicados pela enunciação da construção, e, assim, antecedente e consequente são, ambos, factuais.

Em (3), König (1985a; 1985b; 1986) distingue um terceiro tipo de relação adverbial que compartilha traços das condicionais e das concessivas: as concessivocondicionais, também chamadas de concessivas impróprias. $\mathrm{Na}$ enunciação de construções concessivo-condicionais, somente o consequente $q$ é implicado, ou seja, ao se enunciar mesmo se p, $q$, por exemplo, o antecedente é hipotético, e o consequente é factual. Dessa forma, enquanto construções condicionais são tipicamente hipotéticas, e construções concessivas são tipicamente factuais, construções concessivo-condicionais são tipicamente semifactuais. Neste trabalho, a atenção se centra, exclusivamente, nas construções concessivas e nas construções concessivo-condicionais. 
(2)

\section{Condicionais}
(a) forma típica: se p, então $q$
(b) implicação: -

\section{Concessivo-condicionais}
(a) forma típica: a. quer $p$ ou não- $p, q$
b. $(V x)\left(\right.$ se $\left.p_{x}, q\right)$
c. mesmo se $p, q$

(b) implicação: q

\section{(4) Concessivas}
(a) forma típica: embora $p, q$
(b) implicação: p,q

A natureza das orações concessivas, conforme sugere Harris (1988), deve ser avaliada a partir de quatro propriedades: (i) um antecedente concessivo "contém um fato ou uma noção apesar do qual a proposição principal se mantém” (BURNHAM, 1911, p. 4 apud HARRIS, 1988, p. 72); (ii) "em concessivas, contrariando nossa expectativa justificável, a escolha do disjunto é totalmente irrelevante, pelo menos para o resultado na oração principal' (HAIMANN, 1974, p. 357 apud HARRIS, 1988, p. 72); (iii) "numa sentença concessiva, afirma-se a verdade da oração principal, apesar da proposição contida na oração subordinada" (MITCHELL, 1987, p. 706 apud HARRIS, 1988, p. 72); (iv) "um conectivo concessivo implica que o antecedente e o consequente são normalmente incompatíveis" (KÖNIG, 1985b, p. 366).

Essas quatro propriedades se fazem presente nas construções com ainda que listadas em (5).

(5) a O deputado e economista Antônio Delfim Netto gostou das medidas de ajuste, ainda que elas necessitem de uma análise mais detalhada. "Antes tarde do que nunca", disse ele. (19N:Br:Recf)

b O bom ator Patrick Tinsit é um executivo que disfarça suas preferências sexuais com a ajuda de uma dona de boate Fanny Ardant (que ganhou o César de melhor atriz por este filme, ainda que não faça lá grandes coisas $)(19 \mathrm{~N}: \mathrm{Br}: \mathrm{Cur})$

c Eu só pensava em ir à praia. Fazia um calor de matar, eu já disse, ainda que, no alto do morro árido e pedregoso, soprasse uma brisa agradável que vinha da costa. (19:Fic:Br:Carvalho:In iciais)

Em (5a), por exemplo, a proposição central de o deputado e economista Antônio Delfim Netto gostar das medidas de ajuste se mantém e é verdadeira apesar da proposição designada pela oração subordinada (essas medidas necessitam de uma análise mais detalhada). Já em (5b), o fato de Fanny Ardant não fazer grandes coisas no filme cria uma série de expectativas, entre elas a de não ganhar o César de melhor atriz; esse disjunto, entretanto, figura como irrelevante, já que a oração principal descreve um resultado que contraria essa expectativa. Em (5c), por fim, a articulação se dá entre dois fatos que, normalmente, não se dariam conjuntamente: o fato de soprar uma brisa agradável que vinha da costa é incompatível, para o falante, com o fato de fazer um calor de matar; essa incompatibilidade, entretanto, não impede que os dois fatos ocorram simultaneamente. 
König (1985b, p. 4) representa essa incompatibilidade entre antecedente e consequente com o seguinte esquema: embora $p, q \rightarrow$ se $p$, então normalmente não- $q$. Construções concessivas, portanto, são usadas para asseverar duas proposições que contrariam a suposição de que, normalmente, tais proposições não se dão conjuntamente, ou melhor, a situação descrita em uma oração é uma condição desfavorável para a situação descrita na outra oração (HASPELMATH; KÖNIG, 1998, p. 566). As orações introduzidas por ainda que em (5) e (6) se enquadram nesse esquema e, assim, figuram como casos de orações concessivas.

(6) a E quando você faz uma política pública, no caso uma política de ação afirmativa, ainda que não seja uma política de alcance, de contingência nacional, encontra reações. (190r:Br:Intrv:Web)

b Este será um momento bem positivo, com possibilidades de realizações muito grandes em termos pessoais. Ainda que você não queira, isso vai determinar novo rumo para sua vida íntima. Satisfação no amor. (19N:Br:PA)

Em (6a), o fato de ser uma política de alcance, de contingência nacional impediria, normalmente, a realização do evento de encontrar reações; entretanto, para a realidade descrita em (6a), a proposição central ocorre independentemente da situação desfavorável descrita pela proposição expressa na oração subordinada. $\mathrm{O}$ mesmo se aplica a (6b): o fato de você não querer impediria, normalmente, o evento de isso determinar novo rumo para sua vida íntima; entretanto, para a realidade ali descrita, esse impedimento não surte efeito. Assim, em (7), podemos representar os exemplos em (6) conforme o esquema da concessão.

(7) a se não é uma política de alcance, de contingência nacional $(p) \rightarrow$ então normalmente não encontra reacões $(q)$

b $\quad$ se você não quer $(p) \rightarrow$ então normalmente $\underline{\text { isso }}$ não vai determinar novo rumo para sua vida íntima $(q)$

Já as construções concessivo-condicionais, em virtude de sua natureza e dos traços que compartilham, podem ser situadas junto a um espaço nocional entre a condicionalidade e a concessividade.

Em relação aos traços condicionais, as construções concessivo-condicionais estabelecem um vínculo condicional entre prótase (ou oração subordinada), oração que exprime condição, e apódose (ou oração principal), oração que exprime o que é condicionado. A diferença entre condicionais e concessivo-condicionais recai sobre a natureza da prótase: nas construções concessivo-condicionais, ao contrário das construções condicionais comuns, não é somente uma única prótase que se articula à apódose; a apódose, na verdade, articula-se a um conjunto de prótases expressas explícita ou implicitamente pela oração concessivo-condicional, conforme demonstra a seguinte representação: Se $\{\mathrm{a}$ ou b ou c ou d...\}, então q.

Nesse sentido, Haspelmath e König (1998) optam por distinguir, a depender da natureza da prótase, três tipos de concessivo-condicionais: (i) concessivo-condicionais alternativas (cf. (8a)), (ii) concessivo-condicionais universais (cf. (8b)) e (iii) concessivo-condicionais escalares (cf. (8c)). 
Whether we get any financial support or not, we will go ahead with our project.

(Quer consigamos qualquer apoio financeiro ou não, seguiremos com nosso projeto.)

b Concessivo-condicionais universais

No matter how much financial support we get, we will go ahead with our project.

(Independente do quanto consigamos de apoio financeiro, seguiremos com nosso projeto.)

c Concessivo-condicionais escalares

Even if we do get any financial support, we will go ahead with our project.

(Mesmo se conseguirmos qualquer apoio financeiro, seguiremos com nosso projeto)

(adaptado de HASPELMATH; KÖNIG，1998， p. 563)

A prótase de concessivo-condicionais alternativas contém uma junção de dois segmentos condicionais que se diferem pelo fato de o segundo segmento ser a versão negada do primeiro. Em (8a), por exemplo, a prótase da construção concessivocondicional ali exemplificada alterna dois eventos condicionantes, diferentes entre si por sua natureza polar: o de conseguir qualquer apoio financeiro e o de não conseguir qualquer apoio financeiro. Portanto, o conjunto de prótases expresso por orações concessivo-condicionais alternativas é especificado por uma disjunção entre a prótese $p$ e sua negação, conforme demonstra o esquema $S e$ ( $p$ ou não-p), então $q$. A paráfrase de (8a), contida em (9a), revela o valor condicional básico das concessivo-condicionais alternativas, que pode ser representado conforme o esquema lógico em (9b).

(9) a If we get some financial support we will go ahead with our project and if we do not get any financial support, we will go ahead with our project.

(Se conseguirmos qualquer apoio financeiro, nós seguiremos com nosso projeto e se não conseguirmos qualquer apoio financeiro, nós seguiremos com nosso projeto.)

b $\quad(p \vee \sim p) \rightarrow \mathrm{q} \equiv(p \rightarrow q) \&(\sim p \rightarrow q)$

(adaptado de HASPELMATH; KÖNIG，1998， p. 565)

As concessivo-condicionais universais, por sua vez, trazem uma quantificação sobre a variável expressa na prótase, podendo, às vezes, ser confundidas com relativas livres. Sua prótase, portanto, ao trazer uma quantificação sobre a proposição ali designada, deixa implícita uma série de outros valores. Esse valor condicional e quantificador fica evidente quando se parafraseia uma concessivo-condicional universal por uma concessivo-condicional alternativa, conforme demonstra (10a), parafraseando (8b). O esquema lógico em (10b) representa esse tipo de construção concessivocondicional.

(10) a Whether we get a lot of financial support or none at all, we will go ahead with our project.

(Quer consigamos um bom apoio financeiro ou até mesmo nenhum, nós seguiremos com nosso projeto.)

b $\quad(\forall x)\left(\right.$ se $p_{x}$ então $\left.q\right)$

(adaptado de HASPELMATH; KÖNIG, 1998，p. 565-566) 
As concessivo-condicionais escalares, por fim, caracterizam a prótase como um valor extremo frente ao conjunto de prótases a que se relaciona a apódose, de modo que, ao se asseverar a condição para os casos extremos, implica-se que ela também se aplica aos casos menos extremos. Em (8c), por exemplo, o evento de conseguir qualquer apoio financeiro é uma condição extrema frente a outras condições que, naquele contexto, ficam implícitas; na construção concessivo-condicional escalar ali expressa, o evento de seguir com o projeto se mantém independente da condição extrema expressa pela prótase ou de qualquer outra condição menos extrema que essa prótase implica. $\mathrm{O}$ esquema Mesmo ( $\lambda x$ [se $x$ then $q]$, não-p) representa esse tipo de concessivocondicional.

Já em relação aos traços concessivos, as construções concessivo-condicionais, assim como as concessivas genuínas, incluem, no conjunto de prótases relacionadas à apódose, uma circunstância desfavorável à realização da apódose. Além disso, a apódose (ou oração principal) de uma condicional-concessiva, assim como a apódose de uma concessiva, detêm um caráter factual.

As orações encabeçadas por ainda que em (11) são descritas por Neves (2011, p. 866) como eventuais ou potenciais: segundo a autora, "dada a potencialidade da oração concessiva, não necessariamente se segue a realização/a verdade nem a não realização/a falsidade da oração principal.". Dessa forma, as construções em (11) articulam uma oração subordinada de caráter hipotético a uma oração principal de caráter factual.

Seguindo Hengeveld (1998), podemos dizer que as orações encabeçadas por ainda que em (11) são não-factuais, isto é, elas designam proposições irreais, ou melhor, proposições que, frente à referência temporal instaurada pelo evento expresso na oração principal, não são verdadeiras, mas projeções possíveis para um momento posterior. Tais considerações nos levam a enxergar os exemplos em (11) como construções concessivo-condicionais.

(11) a Para o PAN tampouco será uma vitória, porque ainda que obtenha uma votação nacional de mais de $30 \%$, perderá no Dis trito Federal. (19Or:Br:Intrv:ISP)

b Delfino tinha um grande respeito pela mulher quando resolvia fazer alguma coisa. Sabia, por exemplo, que ela ia discutir o caso dele, Delfino, com padre Estêvão, ainda que o mundo viesse abaixo. (19:Fic:Br:Callado:Madona)

Em (11a), o fato de obter uma votação nacional de mais de $30 \%$ é uma condição desfavorável para a realização da situação de perder no Distrito Federal. A apódose, entretanto, ocorre independentemente da situação desfavorável hipotética expressa na prótase. A prótase, além disso, é caracterizada como um valor extremo entre o conjunto de prótases ali implicado. Já em (11b), a proposição de o mundo vir abaixo figura como uma condição desfavorável para a mulher de Delfino discutir seu caso com padre Estêvão; o evento principal, entretanto, acontece independente dessa condição desfavorável. Tal condição, além disso, figura como uma condição extrema entre tantas outras condições que poderiam também ser desfavoráveis para o potencial acontecimento do evento principal. Tais orações são, dessa forma, concessivocondicionais escalares, já que a prótase, ao assinalar uma condição desfavorável como extrema dentro de uma escala, implica, também, em relação à apódose, outra série de condições desfavoráveis. Conforme Haspelmath e König (1998, p. 592), a escalaridade é uma característica semântica das concessivo-condicionais, e não das concessivas. 
Dessa forma, nos dois exemplos em (11), ficam evidentes: (i) o vínculo condicional entre as orações articuladas por ainda que, uma vez que a realização da apódose é totalmente condicionada à realização da apódose; (ii) a natureza escalar da prótase, especificando um valor extremo para a condição ali expressa; e (iii) o vínculo concessivo entre as orações, já que a articulação se dá entre uma condição desfavorável para a realização da apódose, ou seja, articulam-se dois segmentos incompatíveis.

Portanto, em construções concessivo-condicionais, ainda que apresenta um duplo papel semântico (NEVES, 1999, p. 590): ela expressa uma condição hipotética (valor condicional eventual), cuja relevância para o cumprimento do estado de coisas da oração nuclear é, ao mesmo tempo, negada (valor concessivo).

Segundo Kortmann (1997, p. 203), a concessão, enquanto relação entre orações mais complexa, desenvolve-se tardiamente em relação à causa e à condição. Conforme o próprio autor afirma, subordinadores com leitura secundária de causa ou de condição e leitura primária de concessão são raros de serem encontrados. A polifuncionalidade de subordinadores no domínio CCC está subordinada à seguinte hierarquia implicacional: condicional > concessivo-condicional > concessiva. Assim, um subordinador polifuncional só pode marcar duas das relações alocadas nessa hierarquia implicacional: ou condicional e concessivo-condicional, ou concessiva e concessivo-condicional. No português, nossa defesa é a de que a forma ainda que se enquadra ao segundo caso.

\section{Ideias sobre uma possível trajetória de mudança linguística: o estatuto de ainda que}

Em decorrência do recorte sincrônico a que se atém este trabalho, nossa proposta, nesta seção, é levantar uma hipótese de mudança linguística envolvida na emergência de ainda que e, pautados numa análise inicial, de cunho qualitativo, lançar algumas considerações a respeito do estatuto gramatical dessa perífrase conjuncional.

König (1985b, p. 266), ao investigar as afinidades entre concessivas e outros domínios semânticos, identifica cinco principais fontes históricas para os conectivos concessivos:

(i) quantificadores: segundo König (1985, p. 267), há uma relação muito próxima entre concessividade e quantificação universal, de forma que muitos conectores concessivos contêm um componente que também é usado como quantificador universal (por exemplo, em inglês, a conjunção although e, em português, a conjunção conquanto);

(ii) partículas focais/enfáticas e conjunções temporais/condicionais: em muitas línguas, os conectivos concessivos podem ser originalmente compostos a partir de conjunções temporais e/ou condicionais e, também, a partir de partículas focais aditivas e/ou de partículas enfáticas (no inglês, as conjunções even though e even so são exemplos desses casos, já que as formas even e so, que entram na composição dessas conjunções, podem funcionar como partículas focais aditivas; no português, as locuções mesmo se e mesmo que também podem figurar como exemplos, já que constituemse a partir da partícula enfática mesmo combinada à condicional se, no primeiro caso, ou à integrante que, no segundo); 
(iii) notável co-ocorrência/co-existência: os membros do terceiro grupo implicam notável co-ocorrência ou co-existência entre dois fatos como parte do seu significado literal (como, em inglês, nevertheless, still, yet, todos itens de natureza aspectual imperfectiva);

(iv) “obstinação, conflito, desordem": membros do quarto grupo lexicalizam as noções de conflito, obstinação, dissonância ou reações a tais situações (como in spite of, despite, no inglês, e apesar de (que), no português, que, em sua composição, apresentam um elemento nominal como spite (ódio, rancor) e pesar (desgosto), respectivamente);

(v) factual: os membros do último grupo mantêm relações com os conectivos causais e marcam de alguma maneira o caráter factual das orações articuladas por eles (no alemão, por exemplo, a forma zwar funciona como um advérbio, no sentido de na verdade, e, em uma correlação adversativa, acompanhado da conjunção adversativa aber (mas), pode introduzir uma constatação seguida de uma restrição).

Segundo König (1985b, p. 267), a composição formal dos elementos dos dois primeiros grupos de conectivos aponta claramente para as concessivo-condicionais como origem histórica de sentenças concessivas. Essa hipótese, conforme sugere o autor (KÖNIG, 1985b, p. 270), toma por base as similaridades que os dois grupos de conectivos exibem, principalmente os seguintes fatos históricos e sincrônicos:

(i) tanto concessivo-condicionais como concessivas associam-se à ideia de conflito ou incompatibilidade: enquanto uma concessiva pressupõe uma incompatibilidade entre fatos, uma condicional-concessiva pressupõe um conflito entre uma condição, dentre uma série de condições designada pelo antecedente, e a situação expressa no consequente. Dessa forma, o que muda no desenvolvimento de uma concessivo-condicionais a uma concessiva é a relação do antecedente com o mundo real;

(ii) por outro lado, pensando que as condicionas (tanto as condicionais autênticas como as concessivo-condicionais) não implicam sua prótase, e que as concessivas a implicam, o desenvolvimento de concessivocondicionais em concessivas envolve, necessariamente, a perda de seu caráter hipotético.

Nessa linha de raciocínio, Kortmann (1997, p. 200), lembrando que os limites entre concessivas e concessivo-condicionais é fluido, afirma que, em algumas línguas, concessivo-condicionais com partículas focais podem ser usadas num sentido factual, isto é, como orações concessivas genuínas, o que evidencia $o$ frequente desenvolvimento de conectivos concessivos a partir de conectivos concessivocondicionais.

No português, o item ainda, base de formação da perífrase conjuncional ainda que, apresenta uma natureza multifuncional, e seu uso mais pragmatizado, exemplificado em (12), corresponde a uma partícula focal aditiva (cf. KÖNIG, 1991).

(12) a Analisando as ações culturais do Estado a gente não vê o que via no Governo Joaquim Francisco, que era a Fundarpe e tão somente a Fundarpe fomentando a cultura. Na realidade, hoje tem a Secretaria de Cultura com a embaixada que Ariano desenvolve com maestria; tem a Fundarpe executando o que a gente procurou executar, com deficiências lamentáveis de verba e que conseguiu ainda desenvolver o importante projeto O Livro Por 
um Real, que movimentou todo Estado. Há ainda a Secretaria de Imprensa desenvolvendo ações culturais como marketing para o Estado, como esse Festival de Cuba. Então há, na verdade, três ações culturais, três caminhos, com verbas reservadas para cada uma dessas ramificações, sem que entrem em choque. Então são três cabeças e três corpos. (19Or:Br:Intrv:Com)

b tem a Fundarpe executando o que a gente procurou executar, com deficiências lamentáveis de verba e que conseguiu ainda desenvolver o importante projeto O Livro Por um Real, que movimentou todo Estado (19Or:Br:Intrv:Com)

c JC - O que fez você abandonar a carreira de jogadora? Simone - Não sei muito bem, mas acho que eu já me achava meio velha para aquilo, aos 25 anos. Tinha uma geração de novas jogadoras e eu estava interessada em ensinar. Comecei a trabalhar como treinadora da equipe bauruense e ainda fiz alguns jogos como atleta até 1991. (19Or:Br:Intrv:Cid)

Em (12a-c), ainda, no sentido de além disso ou também, materializa linguisticamente o objetivo comunicativo do falante em demonstrar a seu ouvinte a necessidade de expansão de sua (do ouvinte) informação pragmática a partir das informações já colocadas no registro gradualmente construído junto ao contexto. Em (12a), por exemplo, o falante vem informando ao ouvinte sobre as novas ações culturais do Estado adotadas no novo governo e, após enumerar a Secretaria de Cultura e a Fundarpe, o falante adiciona a referência à Secretaria de Imprensa, assinalando, para seu ouvinte, que tal informação referencial deve ser acrescida ao conjunto de informações que já foram enumeradas. Por outro lado, em (12b), ao informar sobre as ações da Fundarpe, o falante salienta uma peça de informação a ser transmitida, no caso o que a Fundarpe conseguiu, e sinaliza, para o ouvinte, que tal informação deve ser encarada como uma expansão em relação ao que se apresentou anteriormente, isto é, o desenvolvimento do projeto foi uma conquista, isso além da execução de ações com verbas deficitárias. Em (12c), por fim, após explicar alguns motivos que justificam o abandono de sua carreira de jogadora, a falante elucida seus feitos na época, como seu trabalho como treinadora da equipe do baruense e a atuação como atleta em alguns jogos, sendo esta última informação sinalizada, por meio de ainda, como uma expansão informacional a partir do núcleo de informações que se vinha construindo anteriormente e um acréscimo de informação ao conjunto de conhecimentos do Ouvinte.

Com base nessas considerações, e seguindo Ferrari et al. (2011), pode-se afirmar que a função de ainda em (12) é assinalar a existência de uma escala pragmática ancorada no contexto em que aparece o enunciado e situar, no extremo superior dessa escala, a porção informacional por ele escopada. Essa propriedade escalar enquadra ainda entre as partículas escalares absolutas (cf. SCHWENTER; VASISHTH, 2000): ainda marca uma informação como o ponto extremo de uma escala pragmática implicada no contexto.

Com base nas considerações de König (1985a; 1985b) e Haspelmath e König (1998, p. 566), podemos considerar que o desenvolvimento do conector condicionalconcessivo ainda que se dá a partir da partícula escalar ainda. Uma construção condicional-concessiva escalar como Ainda ( $\lambda x$ [if $x$ então $q$ ] not-p) resulta da extração da parte focalizada de uma sentença, em que a partícula escalar ainda se combina com a proposição resultante, isto é, com a sentença analisada dentro da parte focalizada.

Isso evidencia dois distintos componentes envolvidos na mudança linguística do item ainda e na emergência da forma ainda que enquanto conectivo concessivo- 
condicional (cf. HEINE; CLAUDI; HÜNNEMEYER, 1991, p. 72): (i) metáfora, que envolve uma gradativa transferência entre o significado escalar e os significados condicional e concessivo, e (ii) metonímia, que reflete um processo, denominado de reinterpretação induzida pelo contexto, em que um determinado tipo de contexto incita a uma interpretação conceitual específica - o significado escalar de ainda, em contexto de subordinação, passa a ser reinterpretado no domínio conceitual da causalidade, especificamente na zona entre condição e concessão.

Dessa forma, ainda que concessivo-condicional é um estágio intermediário na formação do conectivo concessivo ainda que. Um cline que representa as trajetórias de mudança na emergência da conjunção complexa concessiva ainda que seria: ainda partícula escalar > ainda que conector concessivo-condicional > ainda que conector concessivo. A defesa aqui é que ainda que concessivo apresenta um alto grau de gramaticalidade, e isso pode ser demonstrado, inicialmente, por meio de duas propriedades: (i) domínios conceituais da oração encabeçada por ainda que e (ii) forma verbal da oração encabeçada por ainda que.

Sweetser (1990, p. 111) propõe que a junção sintática de orações pode ser interpretada em três diferentes domínios conceituais: como junção de conteúdos no mundo real (domínio do conteúdo), como junção de premissas no mundo epistêmico (domínio epistêmico) e como junção de atos de fala realizados por meio da enunciação das orações (domínios dos atos de fala).

Orações concessivo-condicionais encabeçadas por ainda que designam, necessariamente, conteúdos proposicionais (cf. (13)). Conteúdos proposicionais, em termos gerais, consistem em construtos mentais do falante, ou melhor, são construtos mentais que não existem no espaço ou no tempo, mas estão presentes na mente daqueles que o criam.

(13) a De acordo com Landau, ainda que fosse possível medir o que se deverá perder de receita por conta da crise, é correta a manutenção do cronograma já traçado. (19N:Br:Recf)

b Talvez por isso mesmo, os antigos limitassem os mandatos executivos ao mínimo, como os romanos, que os fixavam em um ano apenas. Ainda que o chefe de governo fosse o mais idôneo e o mais sábio dos homens, a sua permanência no poder, para além de seu mandato, seria a negação da democracia. Há quem faça confusões, e afirme que nos outros países a permanência no poder é ilimitada. (19Or:br:LF:SP)

Em (13a), o falante admite que a hipotética ideia de uma possibilidade de medir o que se se deverá perder de receita por conta da crise não interfere na manutenção do cronograma já traçado, ideia avaliada por ele como correta. Já em (13b), nota-se que há uma incompatibilidade entre uma situação hipotética construída na mente do falante (a de o chefe do governo ser o mais idôneo e o mais sábio dos homens) e uma situação admitida pelo falante como real (a de a permanência do chefe do governo no poder, para além de seu mandato, ser a negação da democracia).

Esses dois exemplos mostram que, em construções concessivo-condicionais, ainda que articula dois conteúdos de natureza proposicional, isto é, dois conteúdos que necessariamente passam pela avaliação do falante. Dessa forma, a interpretação de construções concessivo-condicionais com ainda que se dá no domínio epistêmico. 
Orações concessivas encabeçadas por ainda que também se articulam no domínio epistêmico (cf. (14a)), e, além disso, podem articular-se no domínio do ato de fala (cf. (14b)).

(14) a A conta, no nome de uma ex-namorada do filho do sócio brasileiro, tinha sido desativada. De início, ficou perplexa, e demorou a aceitar, mas quando passou a receber as ameaças anônimas, que lhe diziam para voltar para os Estados Unidos, entendeu finalmente, ainda que fosse difícil imaginar que ele nunca tivesse lhe dito nada. Desde o início, tudo tinha sido um mero problema de imaginação. (19:Fic:Br:Carvalho:Bebados)

b Ela já tinha partido e nada sofreu. Tenta ultrapassar as convenções, ainda que uma única vez, em nome de algo mais humano. Não te ofendas. Esquece os costumes, o que pensarão de ti, só hoje, só esta vez. Ainda que te pareça obsceno este pedido, nestas circunstâncias, sobre o corpo da tua sobrinha. Somos como nuvens. Elas passam e se misturam, se confundem umas nas outras. Não vamos ficar. (19:Fic:Br:Carvalho:Bebados)

Em (14a), o fato descrito na oração principal, o de entender finalmente, se dá independentemente da situação desfavorável criada na mente do falante, a de ser difícil imaginar que ele nunca tivesse the dito nada. Por outro lado, em (14b), a oração encabeçada por ainda que não traz uma circunstância desfavorável para a proposição expressa na oração principal, mas sim para a ordem que essa oração expressa num âmbito mais discursivo. Assim, em (14b), ainda que articula, na construção concessiva, dois atos de fala.

Traugott (1989), ao delinear como contínuo de mudança semântica a trajetória proposicional > textual > expressivo, traz três tendências gerais para a mudança semântica:

(i) Tendência I: significados baseados na situação externa > significados baseados na situação interna (percebida/cognitiva);

(ii) Tendência II: significados baseados na situação externa ou interna > significados baseados na situação textual e metalinguística;

(iii) Tendência III: significados tendem a se tornar altamente embasados na avaliação subjetiva (crenças/atitudes) em relação à proposição.

As tendências II e III descrevem as mudanças semânticas envolvidas no desenvolvimento do conector concessivo ainda que. Em construções concessivocondicionais, a atuação de ainda que se restringe ao domínio epistêmico, articulando significados altamente calcados na avaliação subjetiva do falante, o que se conforma à terceira tendência. Já em construções concessivas, ainda que, além de atuar no domínio epistêmico, também atua no domínio do ato de fala, de forma que, de um significado baseado na percepção cognitiva do falante, passa a veicular significados de ordem textual e metalinguística, o que se conforma à segunda tendência.

Em relação à forma verbal da oração encabeçada por ainda que, Givón (2001, p. 68), ao tratar da integração de orações no âmbito da complementação, distingue um dispositivo sintático para avaliar o grau de integração de orações: a escala de morfologia verbal, que se dá entre o protótipo verbal finito e o protótipo nominal não-finito. Segundo o autor, o caráter não-finito - ou nominalidade - de uma forma verbal pode ser codificada sintaticamente por meio de marcação reduzida de tempo-aspectomodalidade, de marcação reduzida de concordância pronominal e de forma nominal do verbo. 
$\mathrm{Na}$ utilização desses dispositivos para codificar a escala de complementação, o autor (GIVÓN, 2001, p. 68) faz a seguinte previsão implicacional: quanto mais integrados cognitiva e semanticamente são os eventos principal e completivo, mais nominal - portanto, menos finito - vai aparecer morfologicamente o verbo da completiva. A nosso ver, essa previsão também se aplica à articulação de orações adverbiais e, portanto, às construções concessivo-condicionais e concessivas com ainda que.

Lehmann (1988), nesse sentido, propõe, como um dos parâmetros estruturadores da tipologia de combinação de orações, a dessentencialização da oração subordinada, que avalia o grau em que uma oração subordinada está expandida ou reduzida. Num processo de redução, a oração subordinada perde propriedades de uma oração e gradualmente adquire propriedades nominais. Tempo e aspecto, por exemplo, são categoriais verbais que são reduzidas ou até mesmo perdidas em decorrência da dessentencialização da oração subordinada (LEHMANN, 1988, p. 195). Por outro lado, o verbo se torna não-finito, ou melhor, o verbo se torna cada vez mais nominal.

Entre as construções com ainda que, somente no contexto de construções concessivas ocorre verbos reduzidos em forma nominal, especificamente no gerúndio (cf. (15)).

(15) a Por isso, pensar que na Bolívia seria diferente foi uma grave ilusão, um tremendo erro. Não porque fosse o Monje (Carlos) o seu secretário-geral (do Partido Comunista Boliviano). Sêlo-ia sempre. O fato de Monje querer ele mesmo ser o líder da revolução, ainda que recusando-se a ir para o lugar onde se travava a luta principal, é questão de pormenor. A concepção política é que era diferente. (19Or:Br:Intrv:Com)

b A burrice, no Brasil, tem um passado glorioso e um futuro promissor. * Estatização, no Brasil, é como mamilo de homem: não é inútil nem ornamental. * Optei por ser patriótico, ainda que não sendo popular. Tive de abandonar o culto à deusa-cadela da popularidade. (19N:Br:PA)

O uso do verbo em forma nominal (gerúndio) na oração concessiva com ainda que implica a perda de conjugação pessoal e a dispensabilidade do sujeito. Esses traços formais evidenciam um grau avançado de dessentencialização da oração subordinada e, portanto, um grau intermediário de condensação (ou compressão) de informações lexicais e gramaticais.

A presença de um subordinador e a possibilidade de se reduzir a oração dependente mostra um alto grau de integração entre as orações na construção concessiva com ainda que. A redução de orações concessivo-condicionais parece ser possível, embora, ao serem reduzidas, se fortaleça a leitura concessiva (cf. (16)).

(16) a ainda que não visse mais ninguém, seu Juca Vilanova, grande colecionador de objetos de arte, podia passar o resto da vida vendo os tesouros que acumulou. (19:Fic:Br:Callado:Madona)

b \#ainda que não vendo mais ninguém, seu Juca Vilanova, grande colecionador de objetos de arte, podia passar o resto da vida vendo os tesouros que acumulou.

Em (16a), a proposição não ver mais ninguém tem um caráter hipotético e se mostra como uma condição desfavorável para o cumprimento da proposição presente na oração principal. Trata-se, portanto, de uma construção condicional-concessiva. A 
redução da forma verbal da oração subordinada em (16a) é possível, como se vê em (16b). Entretanto, com a redução, perde-se o caráter hipotético da oração subordinada e constrói-se uma concessiva autêntica. Isso nos permite assegurar que só é possível reduzir o verbo da oração subordinada em construções concessivas, o que, seguindo Lehmann (1988) e Givón (2001), corrobora a existência de um estatuto diferenciado entre ainda que condicional-concessivo e ainda que concessivo.

Em síntese, a distribuição entre os domínios conceituais propostos por Sweetser (1990) e a possibilidade de redução da oração encabeçada por ainda que são dois traços (um semântico e o outro formal, respectivamente) que não só confirmam a polifuncionalidade de ainda que, mas que também evidenciam o alto grau de gramaticalidade de ainda que concessivo. De fato, tais propriedades nos permitem prever que o estatuto gramatical de ainda que concessivo é maior do que o de ainda que concessivo-condicionais.

\section{Considerações finais}

Com este trabalho, ficam, de modo geral, duas importantes considerações: (i) construções com ainda que, em português, apresentam tanto uma leitura concessivocondicional, como uma leitura concessiva, e (ii) o alto grau de integração entre as orações na expressão da concessão e, além disso, a atuação do juntor concessivo ainda que nos domínios epistêmicos e do ato de fala revelam seu elevado estatuto gramatical.

\section{REFERÊNCIAS}

AUWERA, J. van der.; KÖNIG, E. Clause integration in German and Dutch conditionals, concessive conditionals, and concessives. In: HAIMAN, J.; THOMPSON, S. A. (ed.). Clause combining in grammar and discourse. Amsterdam: John Benjamins, 1988. p. 101-133.

BARRETO, T. M. M. Gramaticalização das conjunções na história do português. 1999. 460 f. Tese (Doutorado em Linguística) - Universidade Federal da Bahia, Salvador.

CASTILHO, A. T. Nova gramática do português brasileiro. São Paulo: Contexto, 2010. $768 \mathrm{p}$.

CUNHA, C. F. da; CINTRA, L. Nova gramática do português contemporâneo. 3. ed. Rio de Janeiro: Nova Fronteira, 2001.

DAVIES, M.; FERREIRA, M. Corpus do Português: 45 million words, 1300s-1900s. 2006. Available online at: 〈http://www.corpusdoportugues.org>.

FELÍCIO, C. P. A gramaticalização da conjunção concessiva embora. $2008.180 \mathrm{f}$. Dissertação (Mestrado em Estudos Linguísticos) - Instituto de Biociências, Letras e Ciências Exatas, Universidade Estadual Paulista, São José do Rio Preto.

FERRARI, L.; GIAMMATTEO, M.; ALBANO, H. Operadores de foco: el caso de incluso, hasta, solo y aun. Cuadernos de la ALFAL, n.3, p. 30-41, 2011.

GALBIATTI, M. E. Análise comparativa do processo de gramaticalização das perífrases conjuncionais "agora que" $e$ "já que". 2008. 188 f. Dissertação (Mestrado em 
Linguística e Língua Portuguesa) - Faculdade de Ciências e Letras, Universidade Estadual Paulista, Araraquara.

GIVÓN, T. Sintax: a functional-typological introduction. v. 2. Amsterdam: J. Benjamins, 2001. 519 p.

HARRIS, M. Concessive clauses in english and romance. In: HAIMAN, J.; THOMPSON, S. A. (Ed.). Clause combining in grammar and discourse. Amsterdam: John Benjamins, 1988. p. 71-99.

HASPELMATH, M.; KÖNIG, E. Concessive conditionals in the languages of Europe. In: VAN DER AUWERA, J. Adverbial constructions in the languages of Europe. New York: Mouton de Gruyter, 1998. p. 335-419.

HEINE, B.; CLAUDI, U.; HÜNNEMEYER, F. Grammaticalization: a conceptual framework. Chicago: The University of Chicago Press, 1991. 328 p.

HENGEVELD, K. Adverbial Clauses in the languages of Europe. In: AUWERA, J. Adverbial Construction in the Languages of Europe. Berlin: Mouton de Gruyter, 1998. p. 335-419.

KÖNIG, E. On the history of concessive connectives in English, diachronic and synchronic evidence. Lingua, Amsterdam, v.66, n.1, p. 1-19, 1985a.

Where do concessives come from? On the development of concessive connectives. In: FISIAK, J. (ed.). Historical semantics. Historical Word-formation. New York: Mounton de Gruyter, 1985b. p. 263-282.

Conditionals, concessive conditionals and concessives: areas of contrast, overlap and neutralization. In: TRAUGOTT, E. et al. (ed.). On conditionals. Cambridge: Cambridge University Press, 1986. p. 229-246.

The Meaning of Focus Particles. Routledge: London, 1991. 207 p.

KORTMANN, B. Adverbial Subordination: a Typology and History of Adverbial Subordinators Based on European Languages. Berlin: Mouton de Gruyter, 1997. 425 p.

LEHMANN, C. Towards a Tipology of Clause Linkage. In: HAIMAN, J.; THOMPSON, S. A. (eds.). Clause combinning in grammar and discourse. Amsterdam/Philadelphia: John Benjamins, 1988. p. 275-330.

LONGHIN-THOMAZI, S. R. Um exemplo de (inter)subjetivização na linguagem: a reconstrução histórica de 'ainda'. Estudos Lingüísticos, São Paulo, v.34, p. 1361-1366, 2005.

NEVES, M. H. M. A gramaticalização e a articulação de orações. Estudos Lingüísticos, São José do Rio Preto, v.27, p. 46-56, 1998.

As construções concessivas. In: NEVES, M. H. M. (org.). Gramática do Português Falado: Novos estudos. v. 7. Campinas: Editora da UNICAMP, 1999. p. 545-591.

Gramaticalização de conjunções coordenativas: a história de uma conclusiva. Gragoatá, Rio de Janeiro, v.21, n.21, p. 59-72, 2006.

A difusa zona adverbial: o caso da combinação de orações. Linguistica, Madrid, v.20, p. 25-47, 2008. 
Gramática de usos do português. São Paulo: Editora da UNESP, 2011. 1005 p.

PARRA, B. G. G. Uma investigação discursivo-funcional das orações concessivas introduzidas por aunque em dados do espanhol peninsular. 2016. 169 f. Dissertação (Mestrado em Estudos Linguísticos) - Instituto de Biociências, Letras e Ciências Exatas, Universidade Estadual Paulista, São José do Rio Preto.

SCHWENTER, S. A.; VASISHTH, S. Absolute and relative scalar particles in Spanish and Hindi. BLS, n.26, p. 225-233, 2000.

SWEETSER, E. E. From Etymology to Pragmatics: metaphorical and cultural aspects of semantic structure. Cambridge: Cambridge Universe Press, 1990. 188 p.

TRAUGOTT, E. C. On the rise of epistemic meanings. Language, v.65, n.1, p. 31-55, 1989.

Recebido em: 05/10/2015

Aprovado em: 15/12/2015 